\title{
Life Consumption Monitoring for Electronics Prognostics ${ }^{12}$
}

\author{
Satchidananda Mishra, Sathyanarayan Ganesan, Michael Pecht and Jingsong Xie \\ CALCE Electronic Products and Systems Center \\ University of Maryland \\ College Park, MD 20742 \\ 301-405-5323 \\ sachi@umd.edu,gsat@umd.edu,pecht@calce.umd.edu,jsxie@calce.umd.edu
}

\begin{abstract}
Life consumption monitoring is a prognostic method to assess the remaining life of a product in its actual life-cycle environment by continuously or periodically measuring the product's performance parameters and environmental conditions. This paper discusses a generic process to conduct a life consumption monitoring for electronic products. Two case studies on a circuit card assembly in an automobile under-hood environment are presented as application examples of the process. Temperature and vibration were identified as the dominant factors for the failure of the circuit card assembly. The environmental loads were monitored using a data recorder and the remaining life of the card assembly were estimated using physics-of-failure based stress and damage models. The predicted remaining life of the circuit card assembly correlated well with the measurement results.
\end{abstract}

\section{TABLE OF CONTENTS}

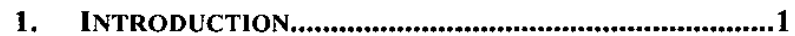

2. Life Consumption Monitoring Procedure ......1

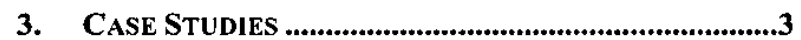

4. LIFE CYCLE ENVIRONMENT AND RESULTS ..............7

5. Results from a CaSe Study in a Similar

ENVIRONMENT

6. CASE STUdY COMPARISON.........................................11

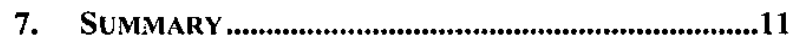

8. REFERENCES ..........................................................

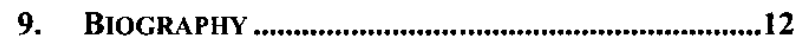

\section{INTRODUCTION}

Condition-based maintenance and health management require information of product life consumption and remaining life. Using the health monitoring approach, the information of a product in its life-cycle environment can be obtained by continuously or periodically monitoring and analyzing the extent of the product's degradation or deviation from its "normal" operating state [1].

Methods for health monitoring include non-destructive tests (e.g., ultrasonic test and visual inspection) and parameters

\footnotetext{
0-7803-8155-6/04/\$17.00@ 2004 IEEE

${ }^{2}$ IEEEAC paper \#1244, Version 4, Updated December 10, 2003
}

to be monitored measure either the health condition (e.g. the oil consumption of an engine) or the stress condition (e.g. vibration) of a product [2][3]. In the extended-range twinengine operations (ETOPS) program for example the ETOPS operators monitor engine conditions to assess adverse trends in engine performance and execute maintenance to avoid serious failures (e.g., events that could cause in-flight shutdowns, diversions, or turnbacks). In some cases, oil consumption data and engine data are combined to identify problems in normal engine operation [4]. In electronic systems, built-in-tests (BIT) are also employed for in-situ health monitoring. Key parameters are tested or monitored using embedded circuits to identify faults and determine the health condition of the system [5].

Life consumption monitoring (LCM) is a prognostic approach in health monitoring, which uses physics-offailure based models to assess the life consumption and the remaining life of a product in its life-cycle conditions. A previous study has proposed a process to conduct life consumption monitoring [6]. However, this process lacked a key procedure to determine and select the environmental and operational parameters that should be monitored. This paper provides an enhanced process to address this issue for electronic products. In addition, two case studies on a circuit card assembly in an automobile under-hood environment are presented as application examples of the process.

\section{Life Consumption Monitoring Procedure}

As shown in Figure 1 the life consumption monitoring process has six steps to estimate the remaining life of an electronic product. These steps include failure modes and mechanisms analysis (FMMA), virtual reliability assessment, critical parameter monitoring, measurement data simplification, stress and damage accumulation analysis, and remaining life estimation. Details for each step are discussed in the subsequent section. 
Step 1: Conduct failure modes, mechanisms and effects analysis

Step 2: Conduct a virtual reliability assessment to assess the failure mechanisms with earliest time-to-failure

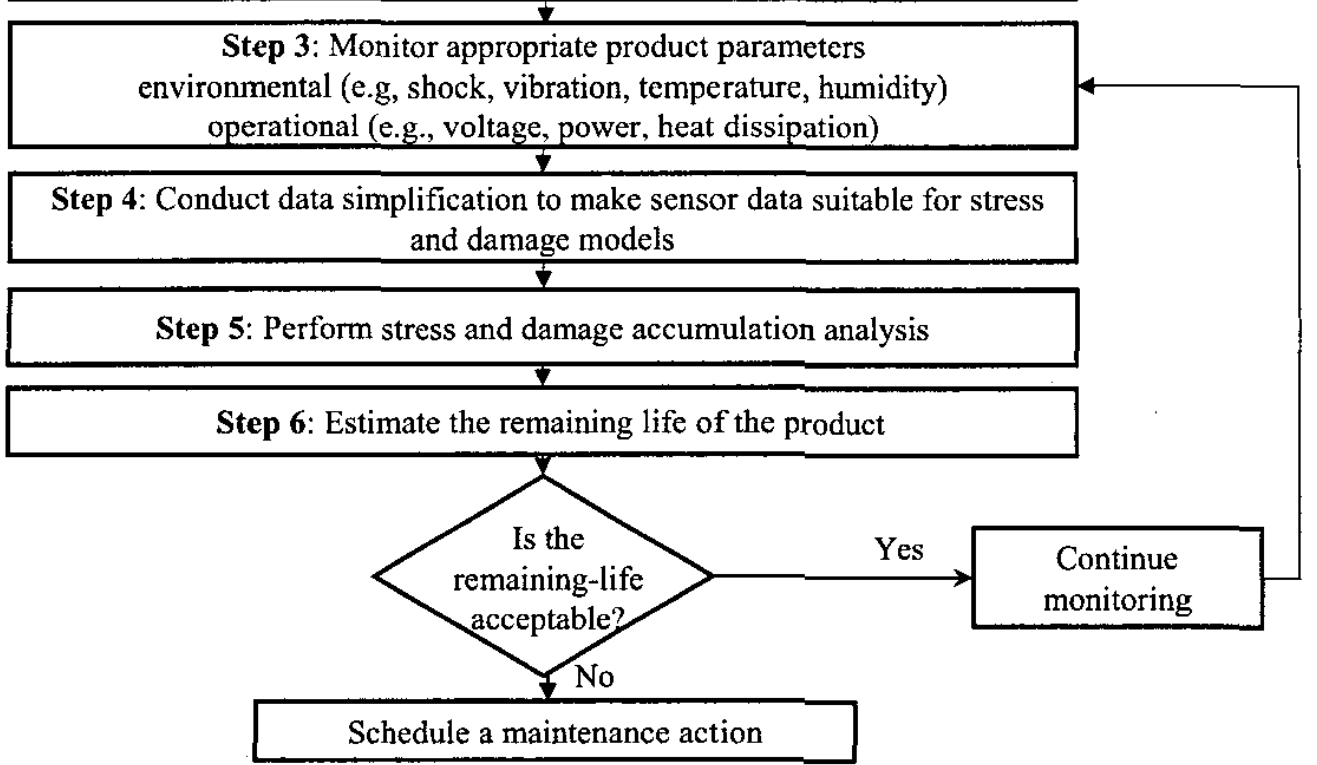

Figure 1: Life consumption monitoring process

\section{Failure Modes and Mechanisms Analysis}

Failure modes and mechanisms analysis (FMMA) is a systematic bottom-up approach to identify potential failures. The objective of conducting a FMMA in life consumption monitoring is to identify potential failure mechanisms that can precipitate a failure in given environmental and operational conditions. The steps involved in FMMA include:

- Identification of geometry, materials and life cycle conditions - This step requires determination of the geometry and materials (along with variability) and the life cycle environment of the product. Life cycle environment of a product includes its assembly, storage, shipping, handling, and usage conditions. Both variations and the worst-case conditions need to be determined.

- Identification of failure modes and corresponding failures sites - All possible failure modes and its corresponding failure sites need to be identified. Different failure modes can be interactive and at different levels.

- Identification of all contributing failure mechanisms Among all potential failure mechanisms, only those that contribute to a failure are selected.

\section{Virtual Reliability Assessment}

Virtual reliability assessment is performed to quantitatively assess the potential failure mechanisms identified in the FMMA. The objective is to identify critical failure mechanisms and corresponding environmental and operational parameters to be monitored.

- Ranking of failure mechanisms based on time-to-failure - This step estimates time-to-failure for each failure mechanism selected in the FMMA, and ranks the failure mechanisms based on the obtained time-tofailure results.

- Identification of critical failure mechanisms - This step identifies the critical failure mechanisms based on the failure mechanism rankings. For a non-repairable unit, the critical failure mechanism is the one in which the first failure is involved. In reality, one failure may occur due to multiple failure mechanisms. Failure mechanisms with time-to-failure less than a product's life expectation are considered as critical failure mechanisms.

- Identification of environmental and operational parameters to be monitored - Here the failure models corresponding to the critical failure mechanisms are identified. The inputs to the failure models in-turn become the candidate environmental and operational parameters to be monitored. 


\section{Product Parameters Monitoring}

Environmental parameters, such as temperature, humidity, pressure, vibration or shock, and radiation, and operation parameters such as current, power and heat dissipation can be monitored continuously or periodically using in-situ sensors. These parameters will be used for degradation evaluation and remaining life estimation.

\section{Data Simplification}

Data simplification is the process of converting the raw sensor data into a form suitable for stress and damage models. The data simplification process depends on the input requirements of stress and damage assessment models. It reduces the number of data to be analyzed and consequently, reduces memory requirement and improves computing speed.

\section{Stress and Damage Accumulation Analysis}

Stress and damage accumulation analysis is used to estimate the damage accumulated in the product. This step begins with creating simulation models based on product geometry and material properties. For example, creating a model for a circuit card assembly requires information on material and dimensions of boards and components and their layout. The simulation model is then used to estimate the stress at individual failure sites based on life cycle environment loads, which subsequently is used to calculate the time-tofailure.

Stress and damage models are based on the input type (cyclic and non-cyclic). Models requiring cyclic inputs are used to determine the fatigue life or damage of a part. Examples of this type include Engelmaier's model for cyclic thermal fatigue, Suhir's model for die fracture, and Pecht and Lall's model for wire fatigue [7]. Models with non-cyclic inputs usually require time varying value of the independent variable as an input. Examples of this type include Black's model for electromigration, Kidson's model for intermetallic formation, and Howard's model for metallization corrosion [7]. To estimate accumulated damage for single/multiple loading conditions a damage accumulation rule is used with the output from stress and damage models. In damage accumulation it is postulated that the damage incurred is permanent, and operation at several different stress amplitudes in sequence will result in an accumulated damage equal to the sum of the damage accrued at each individual stress level. In the linear damage accumulation theory, damage is assumed to accumulate at the same rate at a given stress level regardless of the history. However, damage accumulation may be influenced by the order of application of darnage at various stress levels

\section{Remaining Life Estimation}

Remaining life estimation provides estimation of the remaining life based on accumulated damage of the product. Remaining life estimation involves choosing the right data window for prediction to maximize the system's adaptability to rapid changes in degradation while maintaining an acceptable amount of predictive variability and uncertainty [8]. Based on the remaining life information, the user can decide whether to keep the product in operation with continuous monitoring or to schedule a maintenance action.

\section{Case Studies}

Two case studies were conducted to demonstrate the life consumption monitoring methodology. For each case study, a test board assembly was placed under-the-hood of a 1997 Toyota 4Runner and subjected to normal driving conditions in the Washington DC area. Identical printed circuit boards consisting of eight surface-mount leadless inductors manufactured by ACI AppliCAD Inc were used in each study. The inductors were soldered to FR-4 substrate with $\mathrm{Pb}-\mathrm{Sn}$ eutectic solder. The manufacturer specified operating range of the inductors was $-55^{\circ} \mathrm{C}$ to $125^{\circ} \mathrm{C}$. In the first case study the board was bolted at all the four corners while in the second case the board was bolted only at two comers which made it act like a cantilever to vibrations ${ }^{3}$.

\section{Failure Modes and Mechanisms Analysis}

Failure modes and mechanisms analysis (FMMA) was conducted to assess all possible failure modes and mechanisms of the test board assembly in the automobile underhood environment. Information about product dimensions and geometry were obtained from design specification, board layout drawing and component manufacturer data sheets and environmental and operational parameters were identified based on Society of Automotive Engineers (SAE) environmental handbook. Identified environmental and operational parameters were compared with the existing loading conditions in the underhood environment to determine the potential failure mechanisms. Table 1 shows the failure modes and mechanisms analysis for the circuit card assembly.

\footnotetext{
${ }^{3}$ Cantilever mounting was designed in order to accelcrate the effect of road vibration and is not necessarily representative of the mounting of automobile clectronic modules.
} 
Table 1: Failure modes and mechanisms analysis for the circuit card assembly

\begin{tabular}{|c|c|c|c|c|}
\hline $\begin{array}{l}\text { Failure } \\
\text { Category }\end{array}$ & Failure Site & Failure Mode & $\begin{array}{c}\text { Failure } \\
\text { Mechanism }\end{array}$ & $\begin{array}{l}\text { Environmental and } \\
\text { Operational Stress }\end{array}$ \\
\hline \multirow{4}{*}{$\begin{array}{c}\text { Printed circuit } \\
\text { board (PCB) }\end{array}$} & \multirow[b]{2}{*}{ PTH } & Electrical open & Thermal fatigue & Temperature cycling \\
\hline & & $\begin{array}{c}\text { Electrical short } \\
\text { (between PTHs) }\end{array}$ & $\begin{array}{c}\begin{array}{c}\text { Conductive } \\
\text { filament } \\
\text { formation (CFF) }\end{array} \\
\end{array}$ & $\begin{array}{c}\text { Voltage, high } \mathrm{RH} \text {, and tighter } \\
\text { PTH spacing }\end{array}$ \\
\hline & \multirow{2}{*}{$\begin{array}{l}\text { Metallization } \\
\text { traces }\end{array}$} & \multirow{2}{*}{$\begin{array}{c}\text { Electrical short } \\
\text { (between traces), } \\
\text { and degradation } \\
\text { in resistance } \\
\text { open traces }\end{array}$} & $\begin{array}{c}\text { Electromigratio } \\
n\end{array}$ & $\begin{array}{l}\text { High current density and } \\
\text { temperature }\end{array}$ \\
\hline & & & Corrosion & $\begin{array}{c}\text { High RH, electrical bias, ionic } \\
\text { contamination }\end{array}$ \\
\hline \multirow{3}{*}{ Component } & \multirow{3}{*}{ Inductors } & $\begin{array}{l}\text { Short between } \\
\text { windings }\end{array}$ & Thermal fatigue & $\begin{array}{c}\text { Overheating due to excessive } \\
\text { current and prolonged use at } \\
\text { high temperature }\end{array}$ \\
\hline & & $\begin{array}{c}\text { Short between } \\
\text { windings and the } \\
\text { core }\end{array}$ & Thermal fatigue & $\begin{array}{c}\text { Overheating due to excessive } \\
\text { current and prolonged use at } \\
\text { high temperatures }\end{array}$ \\
\hline & & $\begin{array}{l}\text { Open circuit } \\
\text { inside the } \\
\text { inductor }\end{array}$ & Thermal fatigue & $\begin{array}{l}\text { Prolonged use at high } \\
\text { temperatures }\end{array}$ \\
\hline Interconnect & Solder joints & $\begin{array}{l}\text { Intermittent } \\
\text { change in } \\
\text { electrical } \\
\text { resistance }\end{array}$ & $\begin{array}{c}\text { Thermal fatigue, } \\
\text { creep, high- } \\
\text { cycle fatigue }\end{array}$ & $\begin{array}{c}\text { Temperature cycling and } \\
\text { vibration }\end{array}$ \\
\hline
\end{tabular}

\section{Virtual Reliability Assessment}

Virtual reliability assessment was conducted to assess the time-to-failure using the failure mechanisms and models identified in failure modes and mechanisms analysis (FMMA), including plated through hole fatigue, conductive filament formation, electromigration, metallization corrosion, and solder joint fatigue. Information about product dimensions and geometry were obtained from design specification, board layout drawing and component manufacturer data sheets. Environmental data for analysis including temperature, vibration and humidity were obtained from the Society of Automotive Engineers (SAE) environmental handbook and Washington DC area weather reports.

Figure 3 shows the average power spectral density (PSD) plot for the vibration on a car frame from SAE handbook [15]. The car was assumed to run an average of 3 hours per day. Table 3 shows the temperature data used to define the underhood environment. The maximum relative humidity for the underhood environment was $98 \%$ at $38^{\circ} \mathrm{C}$ [15]. Humidity conditions were used in the estimate of time-tofailure for corrosion and conductive filament formation.
Table 2: Virtual Reliability Assessment

\begin{tabular}{|c|c|c|}
\hline $\begin{array}{c}\text { Failure } \\
\text { mechanism }\end{array}$ & Failure model & $\begin{array}{c}\text { Time-to- } \\
\text { failure }\end{array}$ \\
\hline $\begin{array}{c}\text { Plated through } \\
\text { hole (PTH) } \\
\text { fatigue }\end{array}$ & $\begin{array}{c}\text { CALCE PTH } \\
\text { barrel thermal } \\
\text { fatigue model } \\
\text { (calcePWA) }\end{array}$ & $>10$ years \\
\hline $\begin{array}{c}\text { Conductive } \\
\text { filament } \\
\text { formation (CFF) }\end{array}$ & $\begin{array}{c}\text { Rudra and Pecht } \\
\text { model } \\
\text { (calceFAST) }\end{array}$ & 4.6 years \\
\hline $\begin{array}{c}\text { Electromigration } \\
\text { Black's model } \\
\text { (calceFAST) } \\
\text { moard } \\
\text { traces }\end{array}$ & $\begin{array}{c}\text { Howard's model } \\
\text { Corrosion in }\end{array}$ & 1 year \\
\hline $\begin{array}{c}\text { Solder joint } \\
\text { fatigue }\end{array}$ & $\begin{array}{c}\text { Engelmaier's } \\
\text { thermal fatigue } \\
\text { and Steinberg's } \\
\text { vibration model } \\
\text { (calcePWA) }\end{array}$ & 34 days \\
\hline
\end{tabular}

4 Time-to-failure was obtained in the worst-case conditions with the presence of an clectrolyte. The actual time-to-failure will be much higher than one year. 


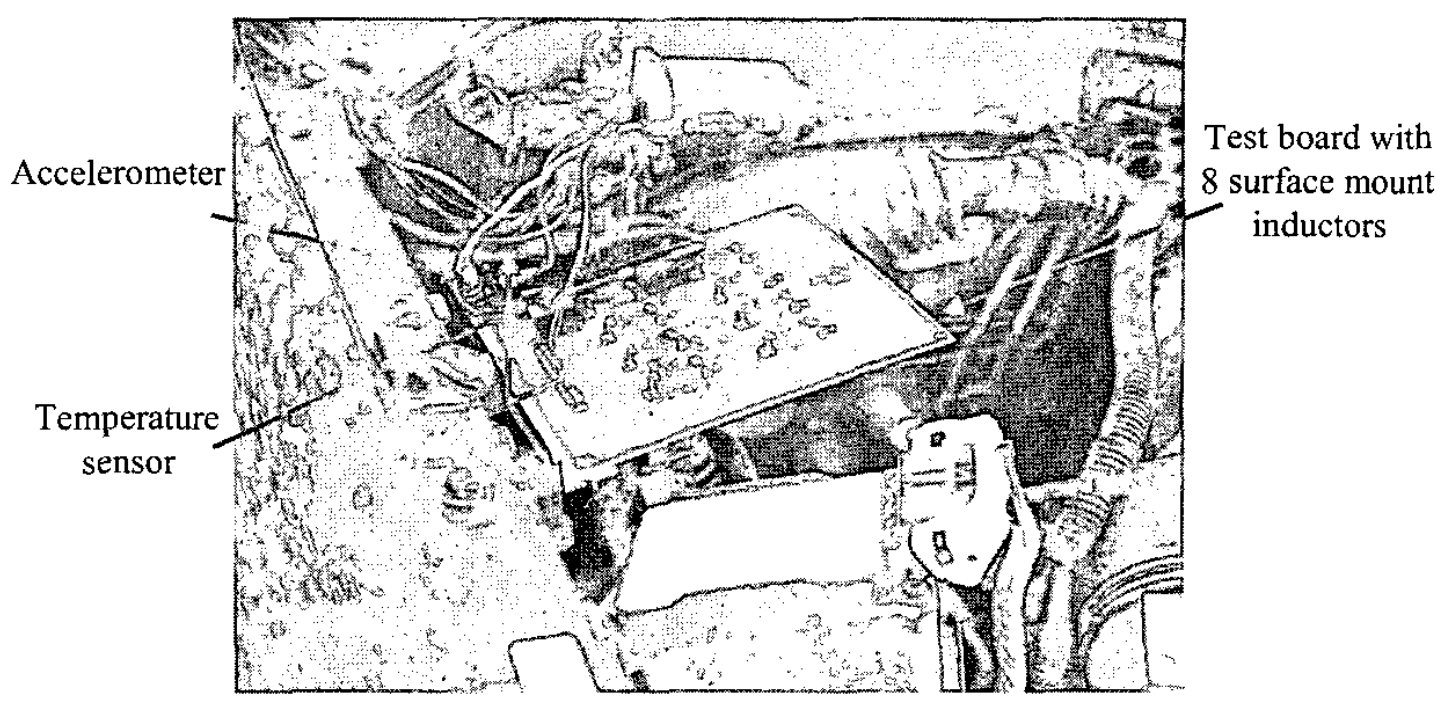

Figure 2: Experimental setup with the test board mounted under-the-hood of a car

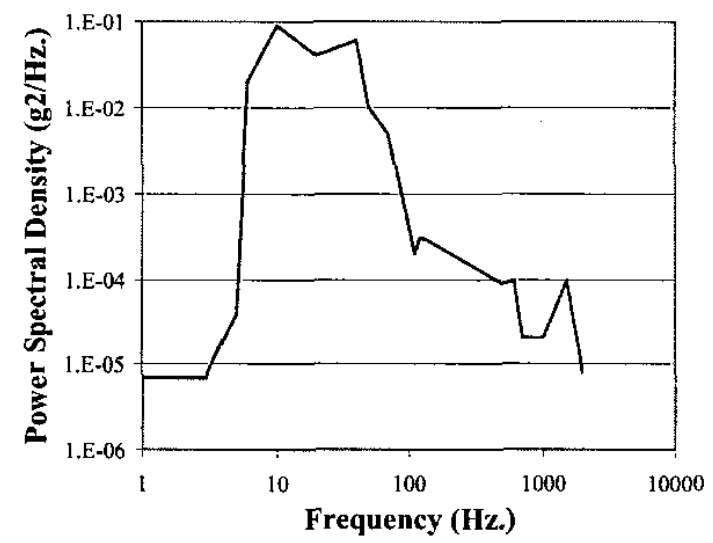

Figure 3: The power spectral density plot used for the virtual reliability assessment [15].

Table 3: Data used to define the temperature environment for the virtual reliability assessment.

\begin{tabular}{|l|c|}
\hline $\begin{array}{l}\text { Maximum under hood temperature } \\
\text { (near the frame) [15] }\end{array}$ & $121^{\circ} \mathrm{C}$ \\
\hline $\begin{array}{l}\text { Average daily maximum } \\
\text { temperature [16] }\end{array}$ & $27^{\circ} \mathrm{C}$ \\
\hline $\begin{array}{l}\text { Average daily minimum } \\
\text { temperature [16] }\end{array}$ & $16^{\circ} \mathrm{C}$ \\
\hline
\end{tabular}

The time-to-failure for the failure mechanisms identified by the FMMA were computed using appropriate failure models. Table 2 shows the time-to-failures for the failure mechanisms obtained from virtual reliability assessment. The time-to-failures are ranked and a risk assessment is made based on the severity and occurrence of the failure modes and mechanisms under consideration. The results show that solder joint fatigue is the only critical failure mechanism in the given life cycle environment. The environmental factors that contribute to solder joint fatigue are temperature cycling and vibration. The virtual reliability assessment predicted 34 days to failure based on solder joint fatigue.

\section{Product Parameter Monitoring}

Monitoring and data simplification schemes were developed for monitoring and analyzing the automobile underhood environment for solder joint fatigue analysis. A battery powered data-recording device was used to record the temperature and vibration environment of the test board assembly. An external temperature sensor was attached to the test board to measure temperature variations in the underhood conditions. Piezoelectric accelerometers were mounted on one of the clamping points of the test board to measure acceleration. 


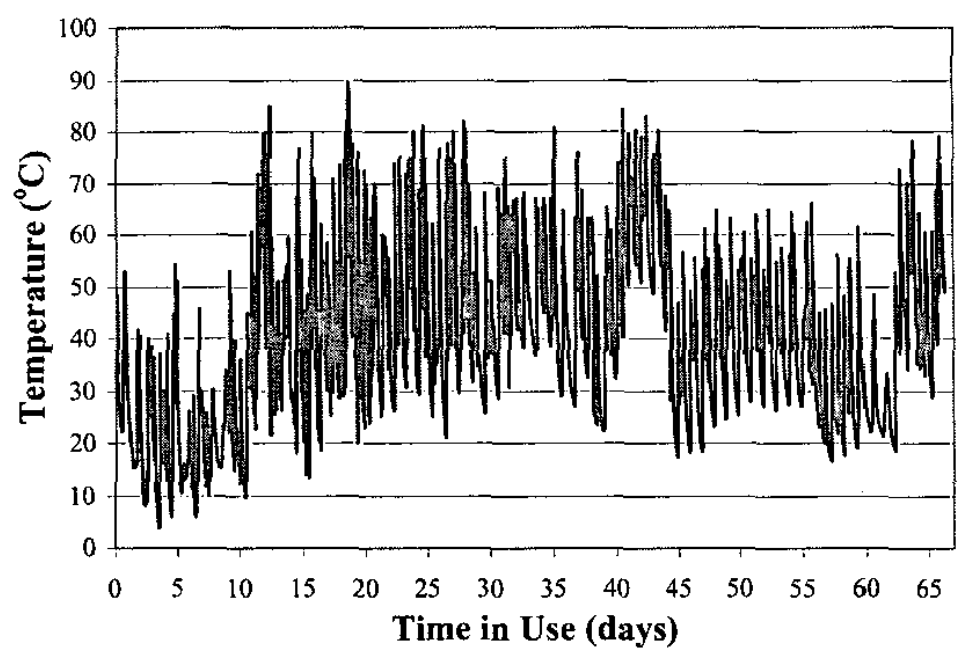

Figure 4: Temperature profile on the test board, as recorded by the data-recording device

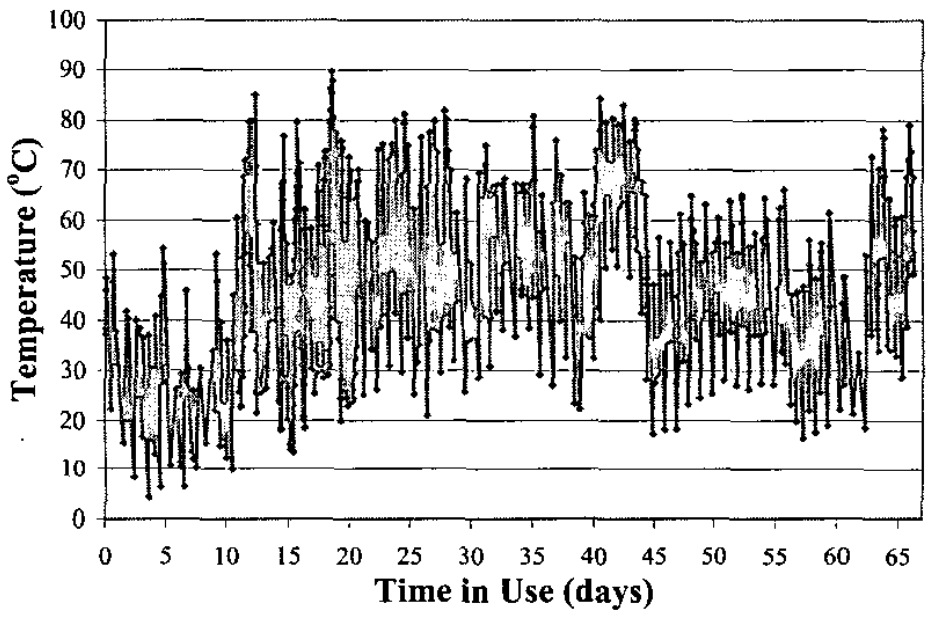

Figure 5: The environmental temperature profile converted to the peaks and valleys using the Ordered Overall Range (OOR) method.

\section{Temperature Data Simplification}

Temperature data is converted to a sequence of peaks and valleys using the ordered overall range (OOR) method [13]. The OOR method is a data simplification method, which allows the user to convert an irregular history into a regular sequence of peaks and valleys. The OOR algorithm can also eliminate some of the temperature reversals, which are potentially less damaging, thereby achieving some data reduction. The algorithm preserves those reversals that differ by at least a specified fraction of the largest reversal in the sequence.
Temperature-based stress and damage models for solder joint fatigue require cyclic input for damage estimation ${ }^{5}$. A temperature cycle is defined by its maximum, minimum temperature, dwell and ramp times Rainflow cycle counting algorithms are used to identify the cycles based on a given loading profile [10]. The 3-parameter rainflow cycle counting method can identify cycles in a manner consistent with input of stress and damage models [11], [12].

\section{Vibration Data Simplification}

The physics-of-failure based reliability assessment models for solder joint failure require the random vibration data to be described in terms of its power spectral density (PSD).

${ }^{5}$ The method described can be applied to simplify environmental data for models that require cyclic input and not restricted to temperaturc. 


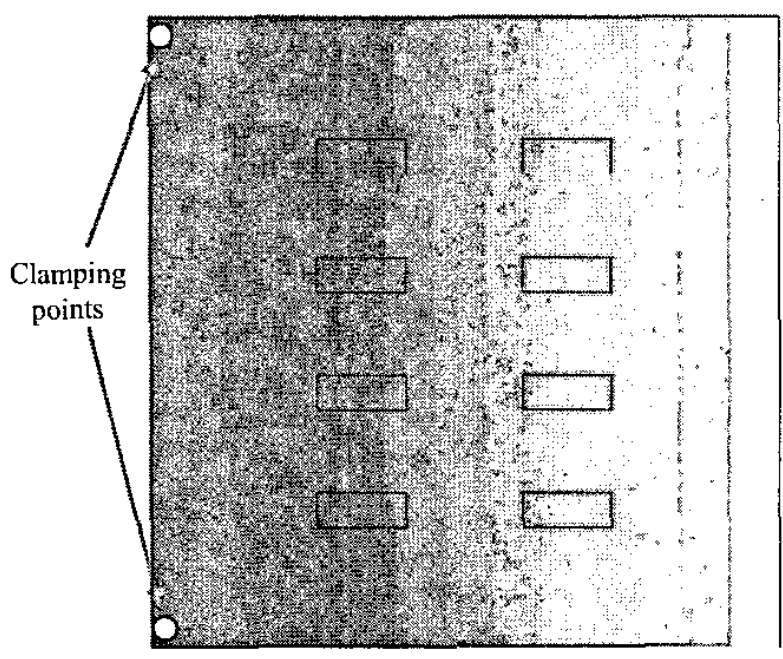

Board displacement (mils)

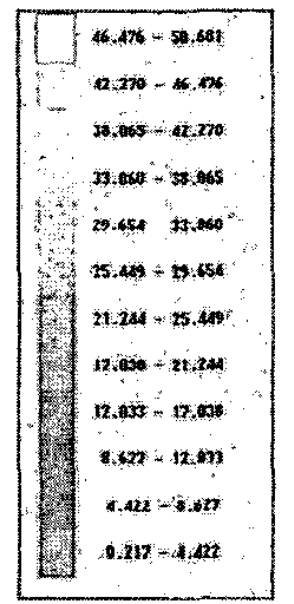

Figure 6: Board displacement estimated by calcePWA caused by the vibration profile.

The PSD describes the frequency composition of the vibration in terms of its mean square value over a frequency range. Fourier transform analysis is used to transform the acceleration data from time domain to the frequency domain. The result of the Fourier transform analysis is usually a plot of amplitude/ power as a function of frequency. In real life collected data is sampled and not continuous. Hence fast fourier transform (FFT) is employed to analyze discrete (or sampled) data. The PSD is estimated by the following equation [14]:

$$
G(f)=\frac{2 h}{N}\left|a_{f}\right|^{2}
$$

where $G(f)$ is the Power spectral density at frequency $f, a_{f}$ is the FFT component of acceleration for frequency $f, h$ is the sampling interval and $\mathrm{N}$ is the number of data points in time domain.

\section{Life CyCle ENVIRONMENT AND RESUltS}

This section discusses the monitored environment and remaining life results for the first case study. (case study-I).

Temperature sensors and accelerometers were used in the automobile under-the-hood environment to monitor temperature, shock, and vibration. The temperature sensor used for the case study was Kele's Model STR-91S twowire strap-on RTD sensor that can measure temperature up to $200{ }^{\circ} \mathrm{C}$. A 3-D piezoelectric (Endevco's Model 2228C) accelerometer was mounted on one of the clamping points of the test board to measure accelerations in all 3 directions (out-of-plane acceleration for the board, acceleration along the car motion and the transverse direction). Figure 2 shows the experimental setup for the case study.

\section{Temperature Analysis}

Figure 4 shows the monitored temperature data on the test board for the entire duration of the experiment. The sampling rate was chosen to be one minute ${ }^{6}$. The figure shows that the maximum temperature seen by the circuit card assembly was $89^{\circ} \mathrm{C}$, which is well below the glass transition temperature of FR-4 $\left(130{ }^{\circ} \mathrm{C}\right)$ and the rated temperature of the inductors $\left(125{ }^{\circ} \mathrm{C}\right)$. The minimum temperature seen by the circuit card assembly was $4^{\circ} \mathrm{C}$.

The temperature vs. time history was converted to an equivalent sequence of peaks and valleys (for thermal fatigue analysis) using the ordered overall range (OOR) method. Figure 5 shows the acquired temperature data converted to peaks and valleys. The sequence temperaturetime history was converted to temperature cycles using the 3-parameter rainflow cycle counting method. The cycle information obtained from the rain flow cycle counting program was used as input to the calcePWA ${ }^{7}$ software and a combined conduction-convection thermal analysis was conducted.

\footnotetext{
${ }^{6}$ The sampling interval for temperature measurement was chosen to be low (i.e., one minute) so that the data recording device can capture temperature changes arising due to starting of the engine

${ }^{7}$ calcePWA is a physics-of-failure based virtual reliability assessment tool developed by CALCE Electronic Products and Systems Center, University of Maryland, College Park. The software creates numerical models for thermal and vibration analysis of printed circuit board assemblies. Based on the results from thermal, vibration analysis and physics-of-failure models, the software cstimates time-to-failure.
} 


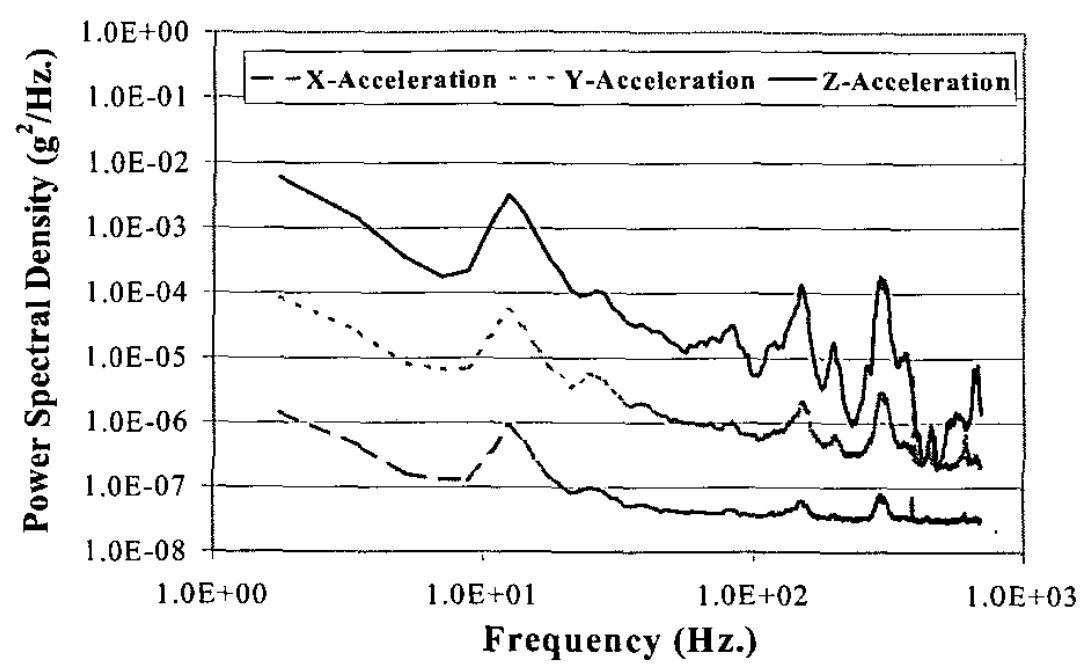

Figure 7: Power Spectral Density (PSD) vs. frequency plots averaged over the duration of the experiment

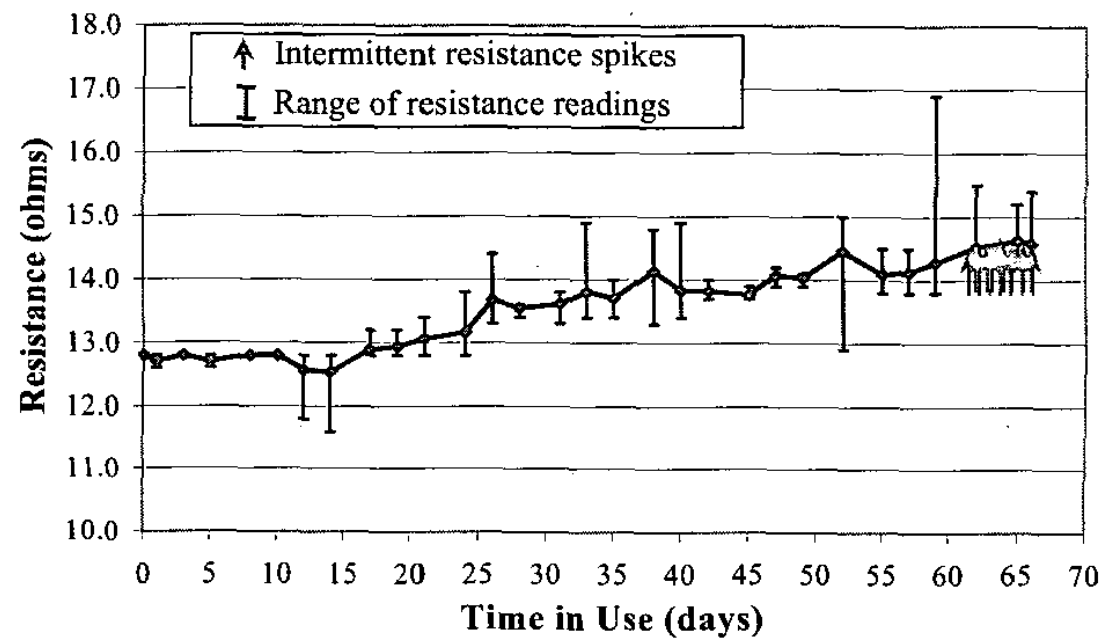

Figure 8: Resistance values of the solder joints. Intermittent resistance spikes are recorded with the help of an event detector circuit. Actual life of the circuit card assembly was found to be 66 days
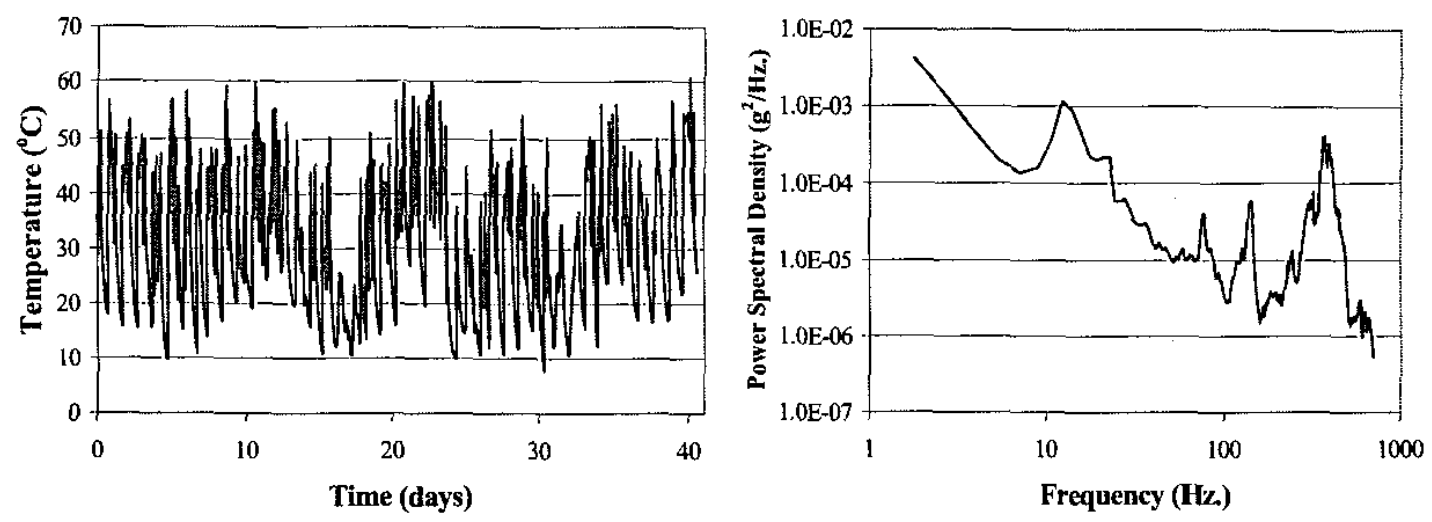

Figure 9: Recorded life cycle environment (temperature and vibration) during an earlier case study 


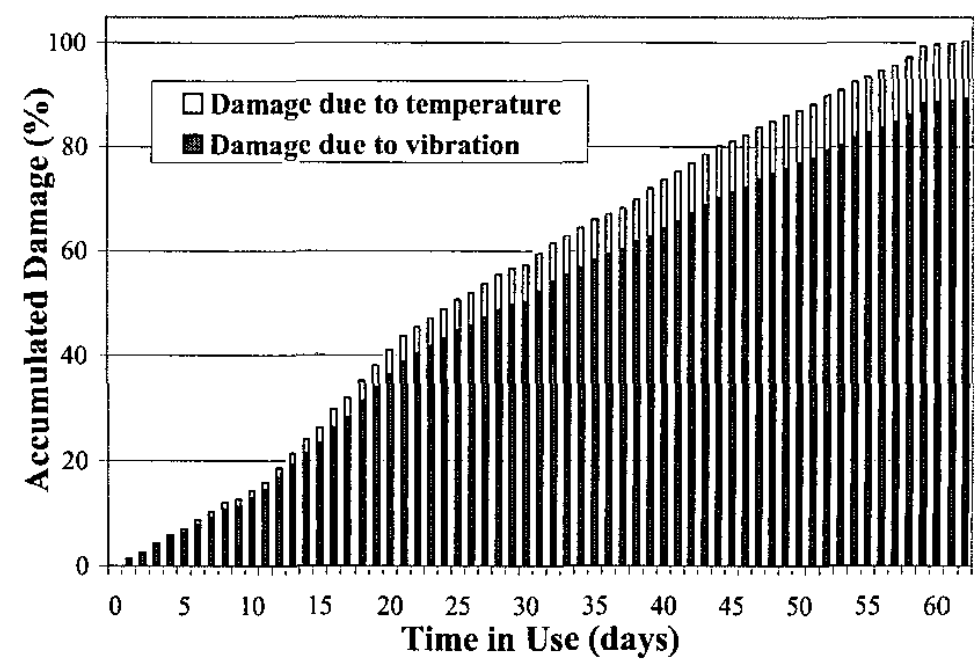

Figure 10: Bar chart showing the accumulated damage estimated using Miner's rule.

\section{Vibration Analysis}

Figure 7 shows the power spectral density (PSD) vs. frequency averaged over the experiment duration. In order to select the vibration analysis range, the data recorder was first programmed to collect data at its maximum sampling rate $^{8}$ of 7200 samples/ second, and the resulting frequency spectrum was analyzed. It was observed that the power spectral density (PSD) of the vibrations was concentrated below $400 \mathrm{~Hz}$ and the PSD was negligible above $600 \mathrm{~Hz}$ (below $10^{-6} \mathrm{~g}^{2} / \mathrm{Hz}$.). Hence, the frequency analysis range was conservatively selected to be 1 to $700 \mathrm{~Hz}$. Accordingly the sampling rate and sample size were selected to be 1800 samples/second and 1024 samples. The anti-alising filter frequency was chosen to be $700 \mathrm{~Hz}$. The out-of-plane vibration was at least 2 orders magnitude higher than the other directions. Hence for simplicity, only out of plane (zdirection Figure 7) in vibration was used for analysis.

The circuit card assembly was modeled with its two clamped points for vibration loading. The displacements of each component were estimated by numerical analysis using calcePWA. Figure 6 shows the estimated displacement of the board caused by vibration. It can be seen from Figure 6 that the gradient of deflection is uniform along horizontal axis of the board, which results in uniform curvature $(1.1 \mathrm{x}$ 10-3 / inch) along the horizontal axis. Uniform radius of curvature results in equal amount of damage accumulation in all solder joints due to vibration.

\section{Stress and Damage Accumulation Analysis}

Damage accumulation in the circuit card assembly was determined using solder joint stress and damage models in calcePWA under the effect of both temperature cycling and

\footnotetext{
${ }^{8}$ This was done to find the frequency range of interest and to ensure that any high-frequency vibrations would not be climinated in the actual experiment.
}

vibration. The output of the 3-parameter rainflow cycle counting algorithm and the power spectral density (PSD) vs. frequency data were used to estimate the damage. The damage accumulation ${ }^{9}$ was estimated using the PalmgrenMiner linear damage accumulation theory [20]. The Palmgren-Miner theory states that the damage fraction $\left(D_{i}\right)$ at any stress level $S_{i}$ is linearly proportional to the ratio of the number of cycles of operation $\left(n_{i}\right)$ to the total number of cycles that would produce failure $\left(\mathrm{N}_{\mathrm{i}}\right)$ at that stress level.

$$
\sum_{j=1}^{i} \frac{n_{j}}{N_{j}} \geq 1
$$

The results obtained from stress and damage analysis are shown in the form of a bar chart in Figure 10. It can be seen from the plot that damage caused by vibration is much higher compared to vibration caused by temperature cycling ( $87 \%$ as opposed to $13 \%$ ).

\section{Remaining Life Estimation}

The remaining life of the circuit card assembly was calculated on a daily basis by subtracting the life consumed on a particular day from the estimated remaining life on the previous day in an iterative manner [19].

$$
R L_{N}=R L_{N-1}-D R_{N} * T L_{N-1}
$$

where $R L_{N}$ is the remaining life at the end of day $N, T L_{N}$ is estimated total life at the end of day $N$ and $D R_{N}$ is the damage ratio accumulated at the end of day $N$. The time interval for the remaining life calculation can be decreased or increased depending on the application and maintenance plan. Figure 12 shows the summary of estimated remaining life for the case study along with the experimental life from Figure 8 . The predicted life based on the life consumption monitoring methodology was 61 days.

${ }^{9}$ Estimated damage of $100 \%$ damage corresponds to the predicted end-oflife of the board. 


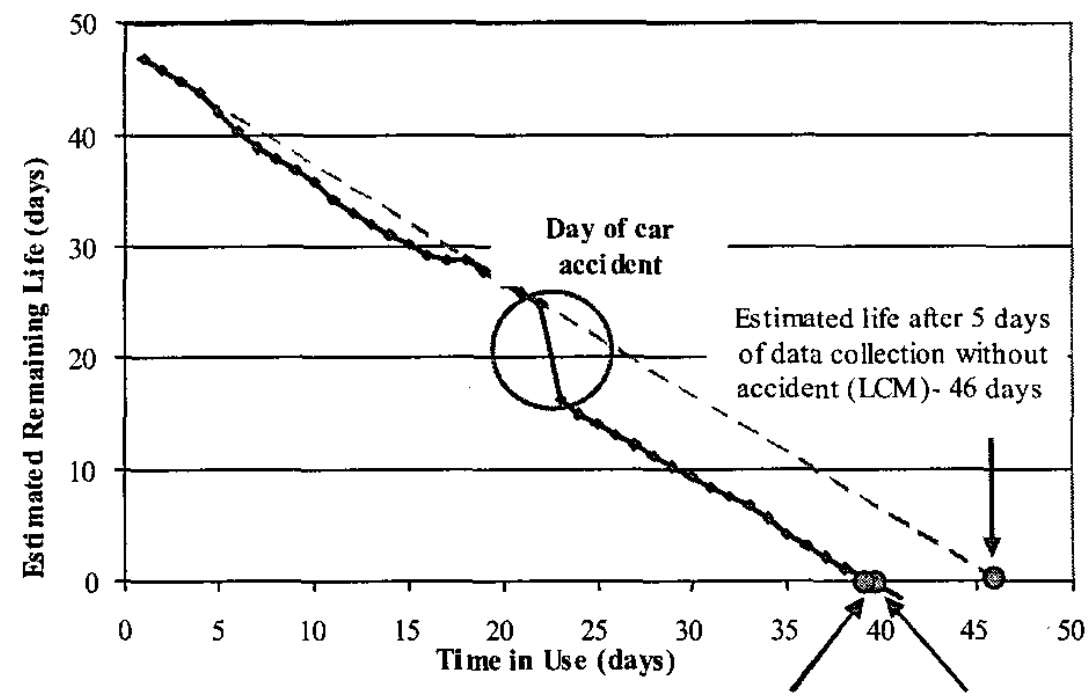

Actual life from resistance Estimated life immediately monitoring - 39 days after accident (LCM) 40 days

Figure 11: Plot of estimated remaining life as a function of time

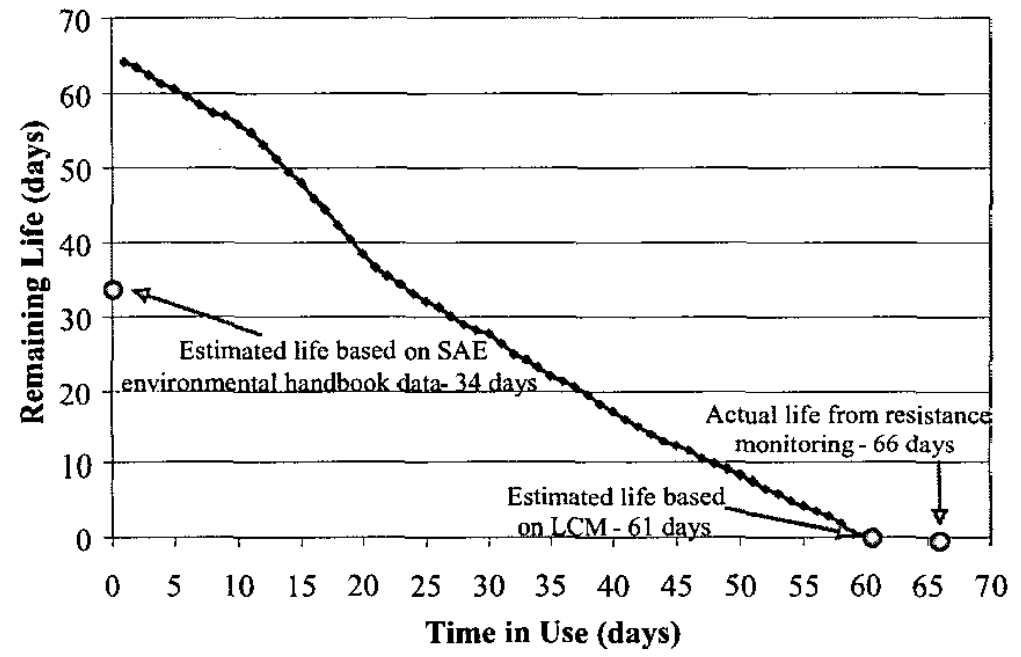

Figure 12: Estimated remaining life of the circuit board assembly as a function of time

\section{Verification of Remaining Life}

The first sign of fatigue failure of solder joints is not necessarily an electrical open, the solder joint failure often manifests itself during thermal and mechanical transients, as a disturbance in the form of a short duration resistance spike. Fortunately, the thermal and vibration fatigue models used for the analysis are also based on intermittent resistance spikes, i.e., interruption of electrical discontinuity for small periods of time (more than $1 \mu \mathrm{s}$ ) [21].

For this case study, the functional degradation of the circuit card assembly was monitored experimentally in terms of resistance change of the solder joints. An event detector circuit was connected in series with all the components and solder joints to indicate intermittent resistance changes. The event detector was connected to the data logger to record the time when there was an increase in resistance. An intermittent increase in resistance, termed a "resistance spike" was defined to be an increase in resistance of 100 ohms [17]. Failure was defined as occurrence of fifteen such resistance spikes.

The event detector circuit sends a continuous direct current signal through the daisy-chained circuit containing the inductors and the solder joints in series. Since the inductors offer zero resistance to the direct current, the resistance of the daisy-chained circuit is dependent on the resistance of the solder joints. The resistance offered to the direct current was compared with the preset value (100 ohms increase for each solder joint) 7200 times every second. The comparison results were logged at the end of every second. 
Figure 8 shows the measured "nominal" resistances (measured during the experiment on a daily basis with the car engine off) and the occurrences of the resistance spikes. It can be seen from the plot that there is a gradual change in resistance throughout the experiment. The actual life of the circuit card assembly was found to be 66 days.

\section{Results from a Case Study in a Similar ENVIRONMENT}

This section gives the summary of a similar case study (case study - II) where an identical circuit card assembly was mounted under-the-hood of the same vehicle (1997 Toyota 4-Runner) [19]. A temperature sensor and a single axis piezoelectric accelerometer were used along with the datarecording device to monitor the underhood environment. The experiment was continued until failure of the circuit board assembly. The recorded temperature and the vibration environment for the case study are shown in Figure 9. The accelerometer was used to monitor the out-of-plane acceleration of the circuit card assembly. There was a car accident during the experiment, which resulted in very high level of random vibration. Also two shock profiles (maximum neak to peak acceleration of $45 \mathrm{~g}$ for duration of 100 milliseconds) were recorded.

Remaining life of the circuit card assembly was estimated on a daily basis based on the collected environmental data. Figure 13 shows the estimated remaining life as a function of time. Actual life from resistance monitoring was found to be 39 days, which is close to the predicted value of 40 days obtained from the experiment

\section{Case Study Comparison}

A comparison between the case studies in terms of monitored environment and the predicted results is given in Table 4. It can be seen from the table that higher fraction of damage occurred due to temperature cycling in the circuit card assembly for case study-I ( $13 \%$ as opposed to $5 \%$ ). This can be explained from the recorded temperature data, which shows higher temperature cycling values for case study-I compared to case study-II. It can also be found from the table that damage fraction due to vibration is comparatively less in case study-I. This observation is due to: 1) lower value of power spectral density (PSD) compared in case study-I compared to case study-II and 2) high vibration during the car accident in case study-II.

For both case studies the predicted life of the circuit card assembly based on life consumption monitoring are within 8 $\%$ of the actual experimental life. Also it can be found that the predicted and actual life of the circuit board assembly are higher for case study-I compared to case study-II, which is due to the fact that vibration is the dominant environmental load compared to temperature cycling in the automotive underhood environment and vibration conditions are more harsh in case of case study-II.

Table 4: Comparison between the case studies

\begin{tabular}{|c|c|c|}
\hline & $\begin{array}{c}\text { Case } \\
\text { Study I }\end{array}$ & $\begin{array}{c}\text { Case } \\
\text { Study II }\end{array}$ \\
\hline Temperature & $\begin{array}{l}\text { Avg. } 41^{\circ} \mathrm{C} \\
\text { Max. } 89 \\
{ }^{\circ} \mathrm{C}\end{array}$ & $\begin{array}{c}\text { Avg. } 30^{\circ} \mathrm{C} \\
\text { Max. } 61 \\
{ }^{\circ} \mathrm{C} \\
\end{array}$ \\
\hline Maximum PSD value ${ }^{10}$ & $\begin{array}{l}6.09 \mathrm{e}-3 \\
\mathrm{~g}^{2} / \mathrm{Hz}\end{array}$ & $\begin{array}{l}8.73 \mathrm{e}-3 \\
\mathrm{~g} 2 / \mathrm{Hz}\end{array}$ \\
\hline $\begin{array}{l}\text { Predicted life using life } \\
\text { consumption monitoring }\end{array}$ & 61 days & 40 days \\
\hline $\begin{array}{l}\text { Actual life based on } \\
\text { resistance monitoring }\end{array}$ & 66 days & 39 days \\
\hline $\begin{array}{l}\text { \% Damage due to } \\
\text { temperature cycling }\end{array}$ & $13 \%$ & $5 \%$ \\
\hline$\%$ Damage due to vibration & $87 \%$ & $95 \%$ \\
\hline
\end{tabular}

\section{SUMMARY}

This paper discusses an enhanced life consumption monitoring methodology with defined process to determine failure mechanisms and parameters to be monitored in health monitoring and management of electronic products. It also presents two case studies in an automobile underhood environment as real application examples of the methodology. In the case studies, solder joint fatigue was identified as the only critical failure mechanism. Temperature and vibration were identified as the environmental parameters that needed to be monitored for the life consumption and remaining life estimation. The results showed that the remaining life prediction correlate well with the measurement.

\section{REFERENCES}

[1] Kelkar, N., Dasgupta, D., Pecht, M., Knowles, I., Hawley, M. and D. Jennings, "Smart Electronic Systems for Condition-Based Health Management," Quality and Reliability Engineering International, Vol, 13, pp. 3-7, 1997.

[2] Mobley, R.K., An Introduction to Preventive Maintenance, pp. 1, Van Nostrand Reinhold, New York, 1990.

[3] Mishra, S., Pecht, M., and D. Goodman, "In-situ Sensors for Product Reliability Monitoring", IEEE/SPIE Proceedings of Design, Test, Integration and Packaging of MEMS/ MOEMS, pp. 10-19, Cannes, France, May 2002.

\footnotetext{
${ }^{10}$ Maximum PSD value does not take into account the high vibration (shock) caused during the accident.
} 
[4] The Boeing Company, "ETOPS Maintenance," Aero Magazine, No. 7, July 1999.

[5] Pecht, M., Dube, M., Natishan, M., and I. Knowles, "An Evaluation of Built-In Test," IEEE Transactions on Aerospace and Electronic Systems, Vol. 37, No. 1, pp. 266-272, January 2001.Ramakrishnan, A., and Pecht, M., "Implementing a Life Consumption Monitoring Process for Electronic Product, IEEE Components Packaging and Manufacturing Technology, Vol. 26, issue 3, pp. 625-634, 2003.

[7] Pecht, M., Radojcic, R., and G. Rao, Guidebook for Managing Silicon Chip Reliability, CRC Press, Boca Raton, FL, 1999.

[8] Greitzer, F.L., Ferryman, T.A., "Predicting Remaining Life of Mechanical Systems." Intelligent Ship Symposium, April 2-3, 2001

[9] A. Ramakrishnan, T. Syrus, and M. Pecht, "Electronic Hardware Reliability," in The Modern Microwave and RF Handbook, Boca Raton, FL: CRC Press, 2000, pp. 3-102 to 3-121.

[10] Collins, J., Failure of Materials in Mechanical Design, John Wiley \& Sons, New York, 1993.

[11] Cluff, K.D., "Characterizing the Commercial Avionics Thermal Environment for Field Reliability Assessment," Journal of the Institute of Environmental Sciences, vol. 40, no. 4, pp. 22-28, Jul.-Aug. 1997.

[12] Anzai, H., "Algorithm of the Rainflow Method," pp. 11-20, The Rainflow Method in Fatigue, Butterworth-Heinemann, Oxford, 1991.

[13] Fuchs, H.O., Nelson, D.V., Burke, M.A., and T.L. Toomay, "Shortcuts in Cumulative Damage Analysis," SAE National Automobile Engineering Meeting, Detroit, 1973.

[14] Bendat, S.J. and A.G. Piersol, Random Data: Analysis and Measurement Procedures, WileyInterscience, New York, 1971.

[15] SAE, Recommended Environmental Practices for Electronic Equipment Design, SAE J1211, Rev. Nov 1978.

[16] Monthly Temperature Averages for the Washington, DC region http://www.weather.com/weather/climatology/month ly/USDC0001

[17] IPC, "J-STD-029," Performance and Reliability Test Methods for Flip Chip, Chip Scale, BGA, and other Surface Mount Array Package Applications, February 2000.
[18] MEG-Array, "Solder Joint Reliability Testing Results Summary, IPC-SM-785," http://www.fciconnect.com/pdffiles/highspeed/MEG -Array_IPC-SM-785_Results.pdf

[19] Mishra, S., Pecht, M., Smith, T., McNee, I., and R. Harris, "Life Consumption Monitoring Approach for Remaining Life Estimation", European Microelectronics Packaging and Interconnection Symposium, IMAPS, pp. 136-142, Cracow, Poland June 2002.

[20] Miner, M.A., "Cumulative Damage in Fatigue," Journal of Applied Mechanics, pp. A-159 to A-164, September 1945.

[21] W. Engelmaier, "Generic Reliability Figures of Merit Design Tools for Surface Mount Solder Attachments, IEEE Trans. CHMT, Vol 16, No. 1., pp. 103-112, 1993.

[22] Mishra, S., and M. Pecht, "Remaining Life Estimation for Electronic Products Using Environmental Monitoring" - submitted to IEEE Components and Packaging Technologies

\section{BIOGRAPHY}

Satchidananda 'Satchi' Mishra obtained his Masters degree from CALCE Electronic Products and Systems

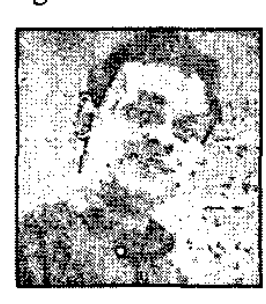
Center, University of Maryland. He has a B.Tech (Hons.) in mechanical engineering from Indian Institute of Technology, Kharagpur, India. Mr. Mishra is currently working with Dell Inc., Austin, TX in the reliability department. He is a member of IEEE and IMAPS.

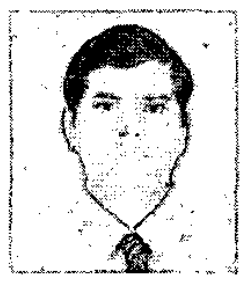

Sathyanarayan 'Sathya' Ganesan is a Masters student and Graduate Research Assistant at CALCE Electronic Products and Systems Center, University of Maryland. He obtained his Bachelors degree in Manufacturing Science \& Engineering from Indian Institute of Technology, Kharagpur, India. He is a member of IEEE and IMAPS.

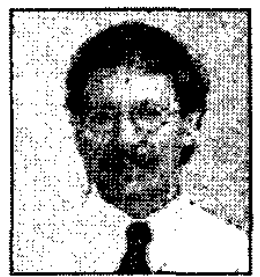

Michael Pecht has a BS in Acoustics, an MS in Electrical Engineering and an $\mathrm{MS}$ and $\mathrm{PhD}$ in Engineering Mechanics from the University of Wisconsin at Madison. $\mathrm{He}$ is a Professional Engineer, an IEEE Fellow, an ASME Fellow, and a Westinghouse Fellow. He served 
as chief editor of the IEEE Transactions on Reliability for eight years and on the advisory board of IEEE Spectrum. $\mathrm{He}$ is the founder and the Director of the CALCE Electronic Products and Systems Center at the University of Maryland and a Chair Professor. $\mathrm{He}$ is chief editor for Microelectronics Reliability and an associate editor for the IEEE Transactions on Components and Packaging Technology. He has consulted for over 50 major international electronics companies, providing expertise in strategic planning, design, test, IP and risk assessment of electronic products and systems.

Jingsong Xie is an assistant research scientist in CALCE Electronic Products and Systems Center at the University of Maryland. Dr. Xie holds a BS in engineering mechanics from Tsinghua University, China, a MS in naval architecture \& ocean engineering from Tokyo University, Japan, and a $\mathrm{PhD}$ in mechanical engineering from the University of Maryland. He was previously a component reliability engineer in Microsoft and a visiting assistant professor in the University of Maryland. His research interest and expertise is in electronic reliability, reliability prediction and electronic component qualification. His work is also in thermal management and EMI/EMC. Dr. Xie is an author of over 20 technical publications and is a member of IEEE, ASME and IMAPS. 